\title{
Condensing Lens on Binocular Indirect Ophthalmoscopy and Slit-Lamp Biomicroscopy
}

\author{
Danang Yoga Wiguna ${ }^{1}$, Sauli Ari Widjaja ${ }^{1,2}$, Wimbo Sasono ${ }^{1,2}$, Muhammad Firmansjah ${ }^{1,2}$, \\ Ima Yustiarini ${ }^{1,2}$, Ady Dwi Prakosa ${ }^{1,2}$, Moestidjab ${ }^{1,2}$, Gatut Suhendro ${ }^{1,2}$ \\ ${ }^{1}$ Department of Ophthalmology, Faculty of Medicine Universitas Airlangga, Dr.Soetomo General Academic Hospital \\ Surabaya, Indonesia \\ ${ }^{2}$ Vitreoretinal Division, Department of Ophthalmology, Faculty of Medicine Universitas Airlangga, Dr.Soetomo General \\ Academic Hospital Surabaya, Indonesia
}

\section{ABSTRACT}

Condensing lens is a lens used as an auxiliary lens in indirect instruments to examines fundus. This lens is used with binocular indirect ophthalmoscope and slit-lamp biomicroscope to reach a stereopsis image of fundus. Optical principle of condensing lens is to make eye in myopic condition, so it can produces a real, aerial, inverted and reversed image. This lens was placed between instruments and eye of the patient which located closer to patient's eye. Optimalized position of the lens can produce a good fundus image.

Condensing lens have so many power of dioptre that each power produces different magnification and field of view. High powered lenses produces wider field of view than low powered ones. High powered lens can also used in patient with small dilated pupil and shorter distance of examination. Low powered lenses offer more magnification.

Fundus examination with binocular indirect ophthalmoscope and slit-lamp biomicroscope have purpose to produces stereopsis image because of the binocularity system. These two instruments have each advantages and disadvantages. The advantages of binocular indirect ophthalmoscope are a portable instrument, relatively can be used in uncooperative patient and it can be used with scleral indentation to reach more peripheral view of the fundus. Meanwhile slit-lamp biomicroscope has advantages to offer more magnification and flexible illumination system. With higher powered lens use in biomicroscope, it also give advantages in shorter distance of examination and wider field of view.

Keywords: condensing lens, indirect ophthalmoscopy, fundus examination

Cite This Article: WIGUNA, Danang Yoga. CONDENSING LENS ON BINOCULAR INDIRECT OPHTHALMOSCOPY AND SLITLAMP BIOMICROSCOPY. International Journal of Retina, [S.I.], v. 2, n. 2, sep. 2019. ISSN 2614-8536. Available at: https://www.ijretina.com/index.php/ijretina/article/view/76

https://doi.org/10.35479/ijretina.2019.vol002.iss002.76

\section{INTRODUCTION}

*Correspondence to: Danang Yoga Wiguna Departement of Ophthalmology, Faculty of Medicine, Universitas Airlangga, Dr Soetomo General Academic Hospital Surabaya, Indonesia

danang.yoga.wiguna@gmail.com
Vitreoretinal diseases is one of the main causes of visual impairment and blindness in the world, especially in developing countries. With increasing prevalence of the vitreoretinal cases, developing country governments pay serious attention to all things that can reduce prevalence of the vitreoretinal disorders, especially in early detection of these disorders. This is where importance of diagnostic instruments and availability of competent experts in reducing prevalence ${ }^{1}$.
As one of the diagnostic instruments, condensing lenses play an important role in diagnosing vitreoretinal abnormality. Condensing lens is used as supporting lens on fundal examination with binocular indirect ophthalmoscope and slit-lamp biomicroscope $e^{2}$. Use of condensing lenses has its own difficulties, because the shadows formed are real, upside down and aerial. Right interpretation is needed to conclude inverse fundus shadow. 
In addition, condensing lenses also have varying sizes of dioptric strength that they can produce different field of view and varying magnifications. Deep understanding is needed to choose right condensing lens as well as to interprete findings ${ }^{2,3}$.

\section{CONTENTS}

\section{Working Principle of The Condensing Lens}

Condensing lens works by receiving and focusing light beam emitted by the instrument (illumination beam), collecting and focusing the shadow formed (observation beam) and received by eyes of the examiner. Focus of this beam of light can penetrate turbidity of refraction media as in immature cataract situation ${ }^{3}$.

Working principle of a condensing lens is to make eye become high myopia so as to make focal point in front of the retina. Beam of the light from this focal point is then passed to retina. This light beam is reflected by retina to be refocused by a condensing lens to form a shadow that is located between condensing lens and the examiner ${ }^{3,4}$.
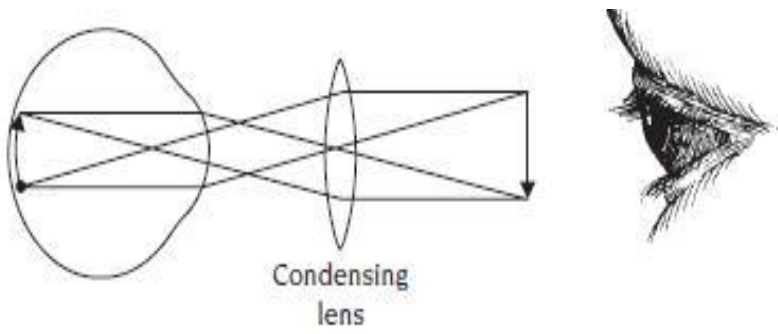

Figure 1. Working principle of condensing lens ${ }^{4}$

Fundus shadow which is located between condensing lens and the examiner, makes shadow become real and reversed. Right interpretation is needed to conclude shadow formed. To determine exact location of the fundus, we have to keep in mind that only beam of the light passes through center of the lens that is not reflected. Part around midpoint is completely inverted from one another, where upper part is bottom side, right part is left side and vice versa ${ }^{3}$.

\section{Magnification of The Condensing Lens}

Magnification is ratio of large aerial fundus shadow compared to patient's fundus magnitude. This ratio is proportional to ratio of the lens's focal point length to patient's eye's focal length. Based on ratio, a formula can be formulated to determine magnification based on strength of the lens used, assuming power of diopters(D) from eyes of emetropia is as big as $60 D^{3,5}$.

Magnification of the examination using a condensing lens can generally be divided into two components, namely magnification from the patient's fundus to the focal point and magnification from focal point to the examiner. First magnification depends on strength of the diopters, while the second magnification depends on distance of the inspection. By combining lens power and inspection distance, magnitude of the total magnification is obtained ${ }^{3,5}$.

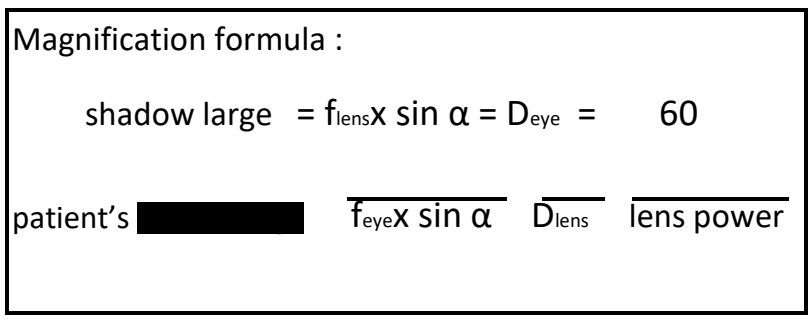

\section{Wide Field of View of The Condensing Lens}

Wider field of view is determined by a beam of the light that radiates from patient's eye that can be captured by the instrument. Larger diameter of the lens, more beam of the light that can be captured, wider field of the view is formed.

Optimal placement of the condensing lens position makes fundus shadow perfectly formed. Distance between the patient's eye to the lens is almost same as distance of the lens to focal point, where focal point is a point where the lens shadow forms. Closer focal point, wider field of view formed ${ }^{3}$.

Based on the theory above, a formula can be formulated to determine extent of the field of view. Wide of the view is directly proportional to diameter and strength of the diopters of the lens. It can be concluded that larger diameter and higher dioptric power of the lens, wider the field of view can be obtained ${ }^{2,3}$.

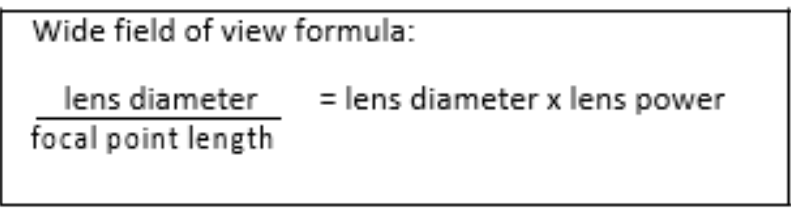

By combining wide field of view and magnification at various sizes strength of the condensing lens, principle can be used as a guideline. Higher strength of the lens diopters, smaller magnification and wider field of the view. With wide field of the view produced, lens with high dioptric strength is relatively more usable for examination with small dilated pupils. In addition, higher dioptric strength, distance between lens to the patient's eye will be closer so that the examination distance is getting closer. This happens because lenses with high dioptric strength have a closer focal point ${ }^{3,6}$. 


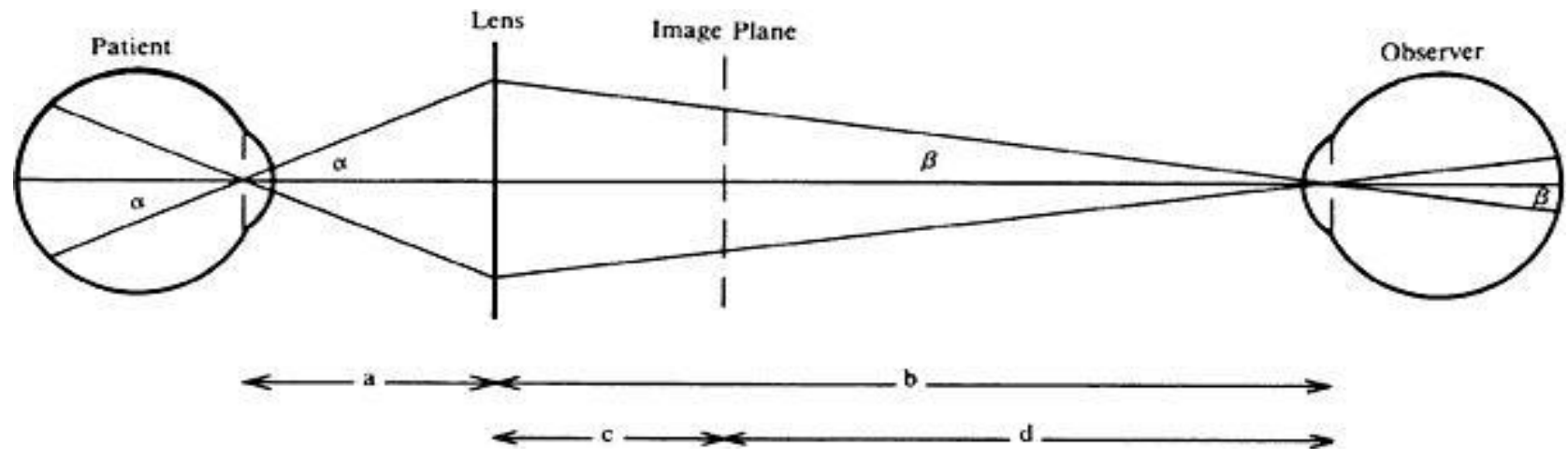

Figure 2. Inspection distance schematic on condensing lens ${ }^{3}$

Table 1. Examination distance on condensing lens ${ }^{3}$

Condensing Lens

C d B

Binoculer Indirect Ophthalmoscope

\begin{tabular}{|c|c|c|c|c|c|c|c|}
\hline \multirow[t]{2}{*}{$+20.00 \mathrm{D}$} & $5 \mathrm{~cm}$ & $25 \mathrm{~cm}$ & $30 \mathrm{~cm}$ & $3.3 \mathrm{D}$ & 16.7 D & $6.0 \mathrm{~cm}$ & $36 \mathrm{~cm}$ \\
\hline & & $40 \mathrm{~cm}$ & $45 \mathrm{~cm}$ & $2.2 \mathrm{D}$ & $17.8 \mathrm{D}$ & $5.6 \mathrm{~cm}$ & $51 \mathrm{~cm}$ \\
\hline \multirow[t]{2}{*}{$+30.00 \mathrm{D}$} & $3.3 \mathrm{~cm}$ & $25 \mathrm{~cm}$ & $28.5 \mathrm{~cm}$ & $3.5 \mathrm{D}$ & $26.5 \mathrm{D}$ & $3.8 \mathrm{~cm}$ & $32 \mathrm{~cm}$ \\
\hline & & $40 \mathrm{~cm}$ & $43.3 \mathrm{~cm}$ & $2.3 \mathrm{D}$ & $27.7 \mathrm{D}$ & $3.6 \mathrm{~cm}$ & $47 \mathrm{~cm}$ \\
\hline \multirow[t]{2}{*}{$+40.00 \mathrm{D}$} & $2.5 \mathrm{~cm}$ & $25 \mathrm{~cm}$ & $27.5 \mathrm{~cm}$ & $3.6 \mathrm{D}$ & $36.4 \mathrm{D}$ & $2.7 \mathrm{~cm}$ & $30 \mathrm{~cm}$ \\
\hline & & $40 \mathrm{~cm}$ & $42.5 \mathrm{~cm}$ & $2.6 \mathrm{D}$ & $37.4 \mathrm{D}$ & $2.6 \mathrm{~cm}$ & $45 \mathrm{~cm}$ \\
\hline \multicolumn{8}{|c|}{ Slit-lamp Biomicroscope } \\
\hline \multirow[t]{2}{*}{ +60.00 D } & $1.7 \mathrm{~cm}$ & $25 \mathrm{~cm}$ & $26.7 \mathrm{~cm}$ & $3.7 \mathrm{D}$ & 56.3 D & $1.8 \mathrm{~cm}$ & $29 \mathrm{~cm}$ \\
\hline & & $40 \mathrm{~cm}$ & $41.7 \mathrm{~cm}$ & $2.4 \mathrm{D}$ & 57.6 D & $1.7 \mathrm{~cm}$ & $43 \mathrm{~cm}$ \\
\hline \multirow[t]{2}{*}{$+78.00 \mathrm{D}$} & $1.3 \mathrm{~cm}$ & $25 \mathrm{~cm}$ & $26.3 \mathrm{~cm}$ & $3.8 \mathrm{D}$ & 74.2 D & $1.3 \mathrm{~cm}$ & $28 \mathrm{~cm}$ \\
\hline & & $40 \mathrm{~cm}$ & $41.3 \mathrm{~cm}$ & $2.4 \mathrm{D}$ & 75.6 D & $1.3 \mathrm{~cm}$ & $43 \mathrm{~cm}$ \\
\hline \multirow[t]{2}{*}{$+90.00 \mathrm{D}$} & $1.1 \mathrm{~cm}$ & $25 \mathrm{~cm}$ & $26.1 \mathrm{~cm}$ & $3.8 \mathrm{D}$ & 86.2 D & $1.2 \mathrm{~cm}$ & $27 \mathrm{~cm}$ \\
\hline & & $40 \mathrm{~cm}$ & $41.1 \mathrm{~cm}$ & $2.4 \mathrm{D}$ & 87.6 D & $1.1 \mathrm{~cm}$ & $42 \mathrm{~cm}$ \\
\hline
\end{tabular}

Information: (a) distance of the lens to eye, (b) distance of the lens to examiner, (c) lens focal point,

(d) distance of the lens focal point to examiner, $(a+b)$ total examination distance, $(1 / a$

$+1 /$ b) power of condensing lens

\section{Examination with Condensing Lens}

Condensing lens is positioned between instrument and the patient's eye, with a distance of about $1-2 \mathrm{~cm}$ in front of the patient's eye. Lens is held using tip of the index finger and surface of the thumb. The third or fourth finger is used as lens fixation on the patient's eyelids or eyebrows. The examiner's wrist is in a moderate flexible state. Lens is moved up and down by increasing or reducing flexion of the index finger. Some condensing lenses, especially on examination with an indirect binocular ophthalmoscope, have a silver or white circle on side facing of the patient ${ }^{4,7}$.

Reflection can arise on the lens because illumination beam goes through same path as the observation beam. This reflection will interfere with formation of the fundus 
shadow. Reflections that arise can be removed by slightly tilting condensing lens. By tilting lens, reflections arising on anterior surface of the lens will be kept away from reflections arising on posterior surface of the lens $s^{4,7}$.

(A)

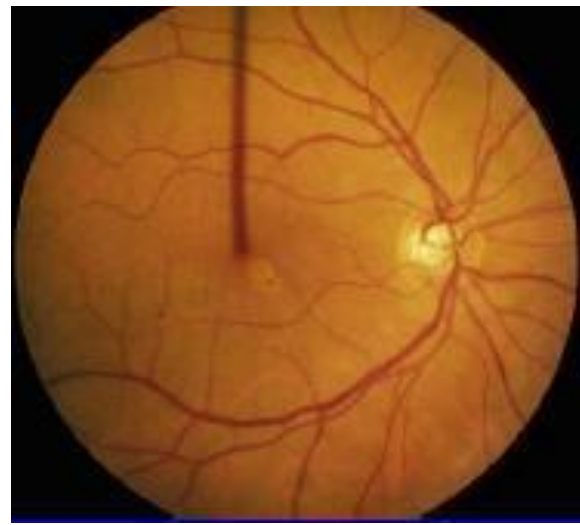

(B)

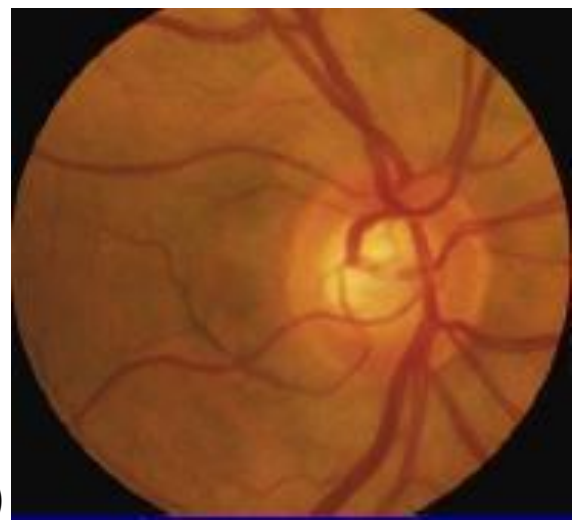

Figure3. Comparison of wide field of view and magnification produce by condensing lens with power of (A) +35.00 D; (B) $+20.00 D^{2}$

Table 2. Comparison of magnification, wide field of view, and examination distance on various power of the condensing lens ${ }^{4}$

\begin{tabular}{|c|c|c|c|c|}
\hline \multicolumn{5}{|c|}{ Condensing Lens Magnification Wide Field of View Examination Distance Inspection Function in General } \\
\hline \multicolumn{5}{|c|}{ Binoculer Indirect Ophthalmoscope } \\
\hline$+14.00 \mathrm{D}$ & $4.2 \times$ & $38^{0}$ & $72 \mathrm{~mm}$ & Fundus lesion \\
\hline$+20.00 \mathrm{D}$ & $3.0 x$ & $50^{\circ}$ & $47 \mathrm{~mm}$ & General screening \\
\hline$+30.00 \mathrm{D}$ & $2.0 x$ & $60^{\circ}$ & - & General screening \\
\hline$+40.00 \mathrm{D}$ & $1.67 \mathrm{x}$ & $69^{\circ}$ & - & - \\
\hline \multicolumn{5}{|c|}{ Slit-lamp Biomicroscope } \\
\hline$+60.00 \mathrm{D}$ & $1.0 \mathrm{x}$ & $76^{0}$ & $10 \mathrm{~mm}$ & Optic disc \\
\hline$+78.00 \mathrm{D}$ & $0.8 x$ & $84^{0}$ & $7 \mathrm{~mm}$ & General screening \\
\hline$+90.00 \mathrm{D}$ & $0.75 x$ & $94^{0}$ & $5 \mathrm{~mm}$ & General screening \\
\hline Super 66 & $1.0 \mathrm{x}$ & $96^{0}$ & - & - \\
\hline Super 90 & $0.76 x$ & $116^{0}$ & - & - \\
\hline
\end{tabular}

\section{Condensing Lens on Binocular Indirect Ophthalmoscopy}

Condensing lens used in indirect binocular ophthalmoscopy has a dioptric strength range that varies with strength between +15.00 to $+40.00 \mathrm{D}$. Choice of the lens depends on magnification and area of the view desired. High dioptric power lenses usually have smaller lens diameter and have shorter working distance ${ }^{3,8}$.

Binocular indirect ophthalmoscope has several advantages compared to the other fundus examination instruments. This instrument has spacious view. Another advantage is that binocular indirect ophthalmoscope is a portable instrument, more practical and allows examination to be carried out in various places. Apart from being practical, this instrument can be used relatively in uncooperative patients, infants and children. This instrument can be used with a sclera indentator to facilitate peripheral fundus examination ${ }^{2,8}$.
Binocular indirect ophthalmoscope also has several disadvantages. This instrument is relatively more difficult to use. Movement of the light source, position, and location of the condensing lens used, and patient's eye position greatly influence the fundus image produced. Magnification produced by binocular indirect ophthalmoscope is also relatively lower compared to other ophthalmoscopes ${ }^{2,8}$.

\section{Condensing Lens on Slit-lamp Biomicroscope}

Condensing lens used in slit-lamp biomicroscope has a dioptric power range that varies between $+60.00 \mathrm{D}$ to +90.00 D. Slit-lamp biomicroscope examination offers advantage of greater magnification with the presence of an enlarged microscope system and a more flexible and stable illumination system with a movable slit-lamp beam. This instrument is mainly for examination of the optic disc and posterior polus ${ }^{9}$. 
Slit-lamp biomicroscope also has several disadvantages including that instrument is not portable and examination requires its own space and place. Examination with this instrument also requires patient to sit and cannot be used in patients who have physical limitations ${ }^{9}$.

\section{Interpretation of Fundus Examination with Condensing Lens}

Condensing lens image that is formed is real, upside down and aerial. Right interpretation is needed to conclude the shadow formed. Part around midpoint is completely inverted from one another, where upper part is bottom side, right part is on left side and vice versa. In describing the location, it is usually used direction of the meridian

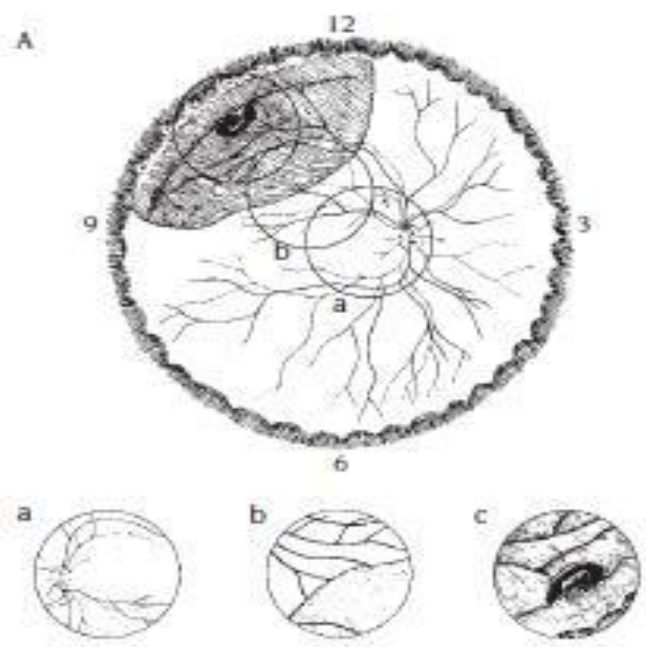

based on clockwise direction and distance from posterior polus based on the diameter of the optic disc or it can also be based on a closer location such as fundus equator and ora serrata ${ }^{3,4}$.

\section{Fundus Chart}

In describing findings of abnormalities in fundus, a fundus chart is needed. This chart consists of three large concentric circles and one small circle in centre of the chart. Large concentric circle consists of an inner circle that shows the fundus equator, middle circle which shows ora serrata and outer circle which shows ciliary process. Small circle in middle shows optic disc ${ }^{4,10}$.

B

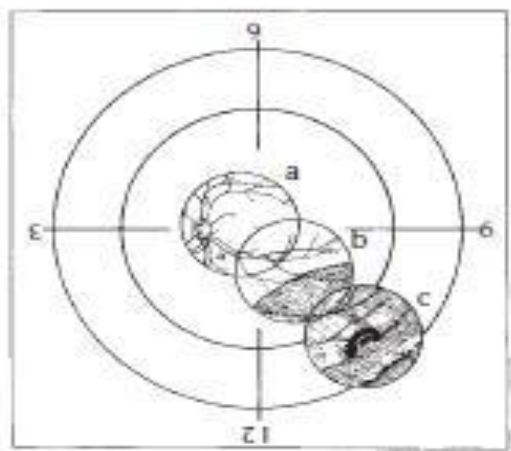

Figure 4. (A) Abnormalities position on fundus; (B) Picture on fundus chart ${ }^{4}$

Main problem in describing abnormalities in fundus chart is orientation. Inverted shadows produced by condensing lenses will make it difficult in fundus depiction. One method that can be used is to rotate fundus chart by $180^{\circ}$. A broad field of view on the patient's fundus can be a separate obstacle in describing abnormalities in fundus chart that has been reversed. We should keep in mind, only fundus image of the condensing lens is reversed, while position of location of the abnormality remains in accordance with the actual one. What needs to be done is to draw abnormalities on chart according to direction of the meridians obtained ${ }^{4,10}$.

\section{Color Code on Fundus Chart}

Writing information on abnormalities obtained is still needed because color is used to describe various kinds of abnormalities that are found in fundus. There is no universal standardization in determining color codes to show abnormalities obtained ${ }^{4,11}$.

Table 3. Color code on retinal drawing ${ }^{4}$

\begin{tabular}{cl}
\hline Color Code & Retinal Abnormalities \\
\hline Blue & Retinal detachment \\
& Retinoschisis (line) \\
& Lattice degeneration (cross-hatched) \\
& Retinal vein (optional)
\end{tabular}


Red

Retinal breaks (blue outline)

Retinal vascularitation (or just retinal)

Retinal bleeding - preretinal, intraretinal, subretinal

Microaneurism, macroaneurism

Attached retina (optional)

Chocolate

Green

Orange

Yellow
Choroid or retinal pigmentation

Hipopigmentation (line)

Photocoagulation (shading or line)

Turbidity of vitreous - bleeding, floaters

Turbidity of refraction media - cataract, cornea (line)

Periretinal Fibrosis

Exudate

Cotton-wool spots

Retinal edema

Optic disc edema or pale disc

\section{CONCLUSION}

Principle works of the condensing lens is to make the eyes become high myopia so as to make focal point of the eye in front of the retina. Resulting fundus shadow is real, upside down, and aerial. Condensing lenses have various sizes of diopters. Higher power of the lens diopters and further distance of the inspection, smaller magnification of the image produced. Higher the dioptric power and lens diameter, wider field of view that is formed.

An examination of the condensing lens on binocular indirect ophthalmoscopy and slit-lamp biomicroscopy has its advantages and disadvantages. Advantages of the indirect binocular ophthalmoscope are portable instruments and can be used in uncooperative patients. Advantage of the slit-lamp biomicroscope is greater magnification with existence of the microscope system and more flexible and stable illumination system.

\section{REFERENCES}

1. Thapa S.S., Thapa R., Paudyal I., Khanal S.P., Aujla J., Paudyal G., et al., 2013. Prevalence and Pattern of Vitreo- retinal disease in Nepal: the Bhaktapur glaucoma study. BMC Ophthalmology, volume 79 no. 19. P.1277- 82.

2. Semes L.P. \& Amos J.F., 2006. Chapter 14: Posterior Segment Evaluation. In: Borish's Clinical Refraction. Philadelphia: Butterworth Heinemann Elsevier. P.511-41.

3. Colenbrander, 2006. Chapter 63: Principles of Ophthalmoscopy. In: Duane's Ophthalmology, volume 1. Philadelphia: Lippincott Williams \& Wilkins. P.15871625.

4. Brinton D.A., 2009. Chapter 3: Ophthalmoscopy. In: Retinal Detachment. New York: Oxford University Press. P.41-74.

5. Miller D., Thall E.H. \&Atebara N.H., 2014. Chapter 2.8: Ophthalmic Instrumentation. In: Ophthalmology, Myron Yanoff\& Jay S. Duker,fourth edition. Philadelphia: Elsevier Saunders. P.57-75.

6. Eperjesi J. \& Ruston D., 2003. Chapter 9: Assessment of the Fundus. In: Investigative Techniques and Ocuar Examination. Philadelphia: Butterworth Heinemann Elsevier. P.75-84.

7. Barnard S. \& Field A., 2000.Binocular indirect ophthalmoscopy Procedures in Comanaged Care, Tutorials. Diunduh dari http://www.academy.org.uk/tutorials/tu torial.htm. 
8. Rosser D., 2010, Binocular Indirect Ophthalmoscopy. 11.Bowling B., 2016. Chapter 16: Retinal Detachment. In: Continuing Education Part 1. General Optical Council. P.14-8.

9. Benjamin L. \& James B., 2007. Chapter 5: Examination of the Retina and Optic Disc. In: Ophthalmology Investigation and Examination Techniques. Philadelphia: Butterworth Heinemann Elsevier. P.45-58.

10. Khurana A.K., 2008. Chapter 12: Optical Instruments and Kanski's Clinical Ophthalmology: Systemic Approach, Eight Edition. Sydney: Elsevier, 2016. P.682-721.

Techniques. In: Theory and Practice of Optics and Refraction, 2nd edition. New Delhi: Elsevier. 